\title{
Ticagrelor - toward more efficient platelet inhibition and beyond
}

This article was published in the following Dove Press journal:

Therapeutics and Clinical Risk Management

\author{
Michał J Kubisa' \\ Mateusz P Jezewski' \\ Aleksandra Gasecka ${ }^{2,3}$ \\ Jolanta M Siller-Matula ${ }^{4}$ \\ Marek Postuła' \\ 'Department of Experimental and \\ Clinical Pharmacology, Centre for \\ Preclinical Research and Technology \\ (CEPT), ${ }^{2}$ Ist Chair and Department \\ of Cardiology, Medical University of \\ Warsaw, Warsaw, Poland; ${ }^{3}$ Vesicle \\ Observation Centre, Laboratory of \\ Experimental Clinical Chemistry, \\ Academic Medical Centre, University \\ of Amsterdam, the Netherlands; \\ ${ }^{4}$ Department of Cardiology, Medical \\ University of Vienna, Vienna, Austria
}

Correspondence: Marek Postuła Department of Experimental and Clinical Pharmacology, Center for Preclinical Research and Technology (CEPT), Medical University of Warsaw, Banacha IB str, Warsaw 02-097, Poland Tel +48221166160

Fax +48221166202

Email mpostula@wum.edu.pl

\begin{abstract}
Novel antiplatelet drugs, including ticagrelor, are being successively introduced into the therapy of atherothrombotic conditions due to their superiority over a standard combination of clopidogrel with acetylsalicylic acid in patients with acute coronary syndromes (ACS). A P2Y12 receptor antagonist, ticagrelor, is unique among antiplatelet drugs, because ticagrelor inhibits the platelet P2Y12 receptor in a reversible manner, and because it demonstrates a wide palette of advantageous pleiotropic effects associated with the increased concentration of adenosine. The pleiotropic effects of ticagrelor comprise cardioprotection, restoration of the myocardium after an ischemic event, promotion of the release of anticoagulative factors and, eventually, anti-inflammatory effects. Beyond the advantageous effects, the increased concentration of adenosine is responsible for some of ticagrelor's adverse effects, including dyspnea and bradycardia. Large-scale clinical trials demonstrated that both standard 12-month therapy and long-term use of ticagrelor reduce the risk of cardiovascular events in patients with ACS, but at the expense of a higher risk of major bleeding. Further trials focused on the use of ticagrelor in conditions other than ACS, including ischemic stroke, peripheral artery disease and status after coronary artery bypass grafting. The results of these trials suggest comparable efficacy and safety of ticagrelor and clopidogrel in extra-coronary indications, but firm conclusions are anticipated from currently ongoing studies. Here, we summarize current evidence on the superiority of ticagrelor over other P2Y12 antagonists in ACS, discuss the mechanism underlying the drug-drug interactions and pleiotropic effects of ticagrelor, and present future perspectives of non-coronary indications for ticagrelor.
\end{abstract}

Keywords: ticagrelor, P2Y12, antiplatelet drugs, myocardial infarction, acute coronary syndromes, pleiotropism

\section{Introduction}

Activation of platelets on a ruptured or eroded atherosclerotic plaque is a key event in atherothrombosis, including acute coronary syndromes (ACS) and acute ischemic stroke (AIS). ${ }^{1}$ Beyond thrombus formation, activated platelets trigger and disseminate vascular inflammation by exposure and release of pro-inflammatory molecules, thereby contributing to the progression of atherosclerosis. Platelet $\mathrm{P} 2 \mathrm{Y} 12$ receptors for adenosine diphosphate (ADP) are essential for platelet activation. ${ }^{2}$ For this reason, dual antiplatelet therapy (DAPT) comprising acetylsalicylic acid (ASA) and antagonists of the P2Y12 receptor is widely used to prevent recurrent ischemic events in patients with ACS.,4 Among the P2Y12 antagonists, clopidogrel has been the standard treatment since its approval by the US Food and Drug Administration in 1997. Findings from recent large-scale clinical trials demonstrated that platelet inhibition with a novel and more potent P2Y12 receptor antagonist, ticagrelor, and prasugrel reduced the rate of ischemic events compared to clopidogrel. ${ }^{5,6}$ Subsequently, ticagrelor and prasugrel have been 
recommended as the first line treatment in both patients with ST segment elevation myocardial infarction (STEMI) and non-ST segment elevation ACS at moderate-to-high risk of ischemic events, regardless of the initial treatment strategy. ${ }^{3,4}$ Clopidogrel in turn should be used only if ticagrelor and prasugrel are not available, or are contraindicated. ${ }^{3,4}$ In contrast to clopidogrel and prasugrel, ticagrelor 1) blocks the P2Y12 receptor reversibly, 2) increases the concentration of adenosine, and in contrast to clopidogrel 3 ) is metabolized independently of the interindividual genetic variability. ${ }^{5}$ Therefore, ticagrelor is being increasingly investigated in patients with ACS, as well as in non-coronary indications.

In this review, we briefly present the pharmacokinetics and pharmacodynamics of P2Y12 antagonists, summarize the current evidence on the superiority of ticagrelor over clopidogrel in ACS, discuss the mechanism underlying the drug-drug interactions and pleiotropic effects of ticagrelor, and present future perspectives of non-coronary indications for ticagrelor.

\section{P2Y I 2 receptor characteristics, P2YI 2 antagonists pharmacokinetics and pharmacodynamics}

P2Y12 receptor is a G-coupled receptor expressed mainly on platelet cells and merely present on microglial cells. ${ }^{7,8}$ Binding of ADP results in receptor activation, inhibition of adenyl cyclase, decrease in cyclic adenosine monophosphate level, and finally platelet aggregation. ${ }^{7}$ Expression of $\mathrm{P} 2 \mathrm{Y} 12$ receptor may vary due to 1 ) substitution in the $P 2 Y 12 R$ coding gene, 2) qualitative abnormalities of the platelet P2Y12R which result in extensive bleeding disorders, and 3) chronic conditions like diabetes mellitus (DM) and chronic kidney disease (CKD) which are associated with high activity of P2Y12R. ${ }^{7,9}$ Although the scope of P2Y12R functions exceeds beyond platelet activity, the primary function of the P2Y12 receptor includes platelet activation and therefore its inhibition evokes interest in the prevention of thrombotic events. ${ }^{8}$

A summary of pharmacodynamic and pharmacokinetic properties of oral P2Y12 antagonists is presented in Table $1 .{ }^{10}$ Clopidogrel is a prodrug. Following oral administration and intestinal absorption of clopidogrel, it is inactivated by esterases and only $15 \%$ of the dose is further metabolized in a two-step process by different hepatic cytochrome $\mathrm{P} 450$ (CYP450) isoenzymes. The response to clopidogrel is highly variable. The most important aspects that influence the response to clopidogrel include genetic factors, comorbidities, with an emphasis on DM and chronic renal failure, as well as adjunctive pharmacotherapy, including proton pump inhibitors, calcium-channel blockers, coumarin derivatives and statins. ${ }^{7}$ Thus, about one-third of the clopidogrel recipients remain resistant to its anti-aggregatory effect - a phenomenon called high on-treatment platelet reactivity. ${ }^{11}$

A third-generation thienopyridine, prasugrel, is also administered as a prodrug, which needs intestinal and hepatic conversion. ${ }^{10}$ However, only one CYP450 step is involved in this process, and prasugrel pharmacokinetics and pharmacodynamics are less dependent on genetic variability. ${ }^{10}$ Prasugrel active metabolite achieves inhibition of platelet aggregation (IPA) within 1 hour after administration. ${ }^{10}$ Consequently, DAPT using this newer P2Y12 inhibitor results in faster, more consistent, and stronger platelet inhibition. ${ }^{10}$

In contrast to both clopidogrel and prasugrel, ticagrelor is a unique non-thienopyridine P2Y12 antagonist, which does not require metabolic activation, binds to the $\mathrm{P} 2 \mathrm{Y} 12$ receptor in a reversible manner, reaches IPA within 30 minutes after administration, and demonstrates pleiotropic effects probably by increasing adenosine concentration and by yet unknown mechanisms. These features likely set ticagrelor in a higher

Table I Pharmacodynamics and pharmacokinetics of oral P2YI2 inhibitors

\begin{tabular}{|c|c|c|c|}
\hline & Clopidogrel & Prasugrel & Ticagrelor \\
\hline Chemical group & Thienopyridine & Thienopyridine & Cyclopentyltriazolopyrimidine \\
\hline Dosage (loading; maintenance), mg & $300 ; 75$ & $60 ; 10$ & $180 ; 90$ \\
\hline Metabolic activation required & Yes & Yes & No \\
\hline CYP responsible for metabolism* & CYP2C19 & CYP3A4/5, CYP2B6 & CYP3A4 \\
\hline Metabolism dependent on CYP phenotype & Yes & No & No \\
\hline IPA, \% & $50-70$ & 90 & 90 \\
\hline Time to reach IPA, $h$ & $\begin{array}{l}\text { 2-4 (depends } \\
\text { on phenotype) }\end{array}$ & I & 0.5 \\
\hline Time to reach $\mathrm{C}_{\max }, \mathrm{h}$ & $0.5-1$ & 0.5 & I.3-2 \\
\hline Reversible binding to ADP receptor & No & No & Yes \\
\hline Pleiotropism & Yes & Yes & Yes \\
\hline Adenosine-related pleiotropism** & No & No & Yes \\
\hline
\end{tabular}

Notes: *Most pharmacodynamically involved CYP; **probably adenosine-related pleiotropism (see "Mechanism underlying the pleiotropic effects of ticagrelor" section). Data from Teng ${ }^{10}$ and Siller-Matula et al. ${ }^{90}$

Abbreviations: CYP, cytochrome P450; IPA, inhibition of platelet aggregation; $C_{\text {max }}$, maximal concentration; ADP, adenosine diphosphate. 
position among the P2Y12 antagonists, and contribute to the wide spectrum of clinical benefits.

\section{Superiority of ticagrelor over clopidogrel in ACS}

Table 2 presents a comparison of the efficacy and safety outcomes between ticagrelor and other P2Y12 antagonists in patients with ACS.

The superiority of ticagrelor over clopidogrel has been initially established based on the results of the multicenter, double-blind, randomized PLATO (Platelet Inhibition and Patient Outcomes) study, which compared ticagrelor and clopidogrel for the prevention of cardiovascular (CV) events in 18,624 patients with ACS, with or without ST segment elevation. ${ }^{5}$ PLATO showed a reduction in the primary efficacy endpoint (a composite of death from vascular causes, acute myocardial infarction [AMI], or stroke) in patients treated with ticagrelor, as compared to those treated with clopidogrel (9.8\% vs $11.7 \%$, respectively, $p<0.001)$ at 12 months. Importantly, no significant difference in the rates of major bleeding was found between the ticagrelor and clopidogrel groups $(11.6 \%$ vs $11.2 \%, p=0.43)$, although ticagrelor was associated with a higher rate of fatal intracranial bleeding, and lower rate of fatal bleeding of other types. The conclusions from PLATO were confirmed in a real-life setting in the Swedish web-system for enhancement and development of evidence-based care in heart disease evaluated according to recommended therapies as well as in several other studies listed in Table 2. ${ }^{12}$ Additionally, a recent meta-analysis of nine randomized clinical trials that included 106,288 patients showed reduced all-cause mortality, CV mortality, rate of AMI and stent thrombosis with ticagrelor, compared to clopidogrel, while the rate of major bleeding between the two groups was comparable. ${ }^{13}$

The benefits of long-term administration of DAPT with ticagrelor were demonstrated in the PEGASUS TIMI 54 trial (Prevention of Cardiovascular Events in Patients with Prior Heart Attack Using Ticagrelor Compared to Placebo on a Background of Aspirin-Thrombolysis in Myocardial Infarction 54), ${ }^{14}$ which randomized 21,162 patients who had had AMI 1-3 years earlier to ticagrelor at a dose of 90 $\mathrm{mg}$ twice daily, ticagrelor at a dose of $60 \mathrm{mg}$ twice daily, or placebo. Both doses were shown to decrease the composite endpoint of CV death, AMI, or stroke $(7.85 \%$ vs $9.04 \%$, $p=0.008$ for $90 \mathrm{mg}$ vs placebo, $7.77 \%$ vs $9.04 \%, p=0.004$ for $60 \mathrm{mg}$ vs placebo) after 33 months of treatment. However, the rate of major bleeding was higher with both doses of ticagrelor (2.60\% with $90 \mathrm{mg}$ and $2.30 \%$ with $60 \mathrm{mg}$ ) than with placebo $(1.06 \%, p<0.001$ for each dose vs placebo), without significant differences in fatal bleeding. Based on

Table 2 Comparison of the efficacy and safety outcomes between ticagrelor and other P2YI2 antagonists in patients with ACS, with or without ST segment elevation

\begin{tabular}{|c|c|c|c|c|c|c|c|c|}
\hline \multirow[t]{2}{*}{ Study (year) } & \multirow[t]{2}{*}{$\begin{array}{l}\text { Patients } \\
\text { (n) }\end{array}$} & \multirow[t]{2}{*}{ Follow-up } & \multicolumn{3}{|c|}{$\begin{array}{l}\text { Efficacy } \\
\text { (CV death + stroke + AMI) }\end{array}$} & \multicolumn{3}{|l|}{$\begin{array}{l}\text { Safety } \\
\text { (major bleeding) }\end{array}$} \\
\hline & & & Ticagrelor & Clopidogrel & $p$-value & Ticagrelor & Clopidogrel & $p$-value \\
\hline \multicolumn{9}{|c|}{ Ticagrelor versus clopidogrel } \\
\hline PLATO $(2009)^{5}$ & 18,624 & I year & $9.8 \%$ & $11.7 \%$ & $<\mathbf{0 . 0 0 1}$ & $11.6 \%$ & $11.2 \%$ & NS \\
\hline PHILO $(2015)^{15}$ & 801 & I year & $9.0 \%$ & $6.3 \%$ & NS & $10.3 \%$ & $6.8 \%$ & NS \\
\hline SWEDEHEART $(2016)^{12}$ & 45,073 & 2 years & $\begin{array}{l}\text { II.7\% } \\
\text { (+ all-cause death) }\end{array}$ & $22.3 \%$ & NS & $\begin{array}{l}5.5 \% \text { (re-admission } \\
\text { on bleeding) }\end{array}$ & $5.2 \%$ & NS \\
\hline Meta-analysis $(2017)^{13}$ & 106,288 & I year & \multicolumn{3}{|c|}{ OR $(95 \% \mathrm{Cl})=0.88(0.8 \mathrm{I}-0.95)$} & \multicolumn{3}{|c|}{ OR $(95 \% \mathrm{Cl})=1.05(0.96-1.15)$} \\
\hline $\begin{array}{l}\text { Real-world comparison } \\
(2017)^{91}\end{array}$ & 401 & I year & $0.7 \%$ & $5.4 \%$ & 0.024 & \multicolumn{2}{|c|}{ OR $(95 \% \mathrm{Cl})=1.45(0.65-3.2 \mathrm{I})$} & 0.365 \\
\hline $\begin{array}{l}\text { High-risk patients with } \\
\text { ACS }(2017)^{92}\end{array}$ & 273 & 6 months & $1.4 \%$ & $2.9 \%-3.3 \%$ & 0.301 & $3.4 \%$ & $4.5 \%-6.5 \%$ & 0.629 \\
\hline \multirow[t]{2}{*}{$\begin{array}{l}\text { ACS and out-of-hospital } \\
\text { cardiac arrest }(2017)^{93}\end{array}$} & 144 & Hospital stay & $25.0 \%$ & $26.2 \%$ & 0.862 & $12.5 \%$ & $11.4 \%$ & 0.685 \\
\hline & & & Ticagrelor & Prasugrel & $p$-value & Ticagrelor & Prasugrel & $p$-value \\
\hline \multicolumn{9}{|c|}{ Ticagrelor versus prasugrel } \\
\hline PRAGUE I8 $(2016)^{94}$ & 1,230 & I month & $4.0 \%$ & $4.1 \%$ & 0.939 & $0.7 \%$ & $0.6 \%$ & $0.85 I$ \\
\hline Meta-analysis $(2017)^{13}$ & 106,288 & I year & \multicolumn{3}{|c|}{ OR $(95 \% \mathrm{Cl})=0.92(0.78-1.08)$} & \multicolumn{3}{|c|}{ OR $(95 \% \mathrm{Cl})=1.20(0.95-1.5)$} \\
\hline $\begin{array}{l}\text { Real-world comparison } \\
(2016)^{24}\end{array}$ & 16,098 & 3 months & $2.9 \%-3.5 \%$ & $1.8 \%-2.5 \%$ & 0.026 & $4.0 \%-4.4 \%$ & $2.9 \%-3.4 \%$ & 0.006 \\
\hline
\end{tabular}

Notes: Efficacy and safety outcomes are reported as \% and significance (p), or OR and 95\% Cl. The significant differences are marked in bold.

Abbreviations: OR, odds ratio; $\mathrm{Cl}$, confidence interval; NS, non significant; CV, cardiovascular; AMI, acute myocardial infarction; ACS, acute coronary syndromes; PLATO, Ticagrelor versus Clopidogrel in Patients with Acute Coronary Syndromes; PHILO, Ticagrelor versus Clopidogrel in Japanese, Korean and Taiwanese Patients with Acute Coronary Syndrome; PRAGUE 18, Prasugrel versus Ticagrelor in Patients with Acute Myocardial Infarction Treated with Primary Percutaneous Coronary Intervention. 
the PEGASUS TIMI 54 trial, it seems that patients with generally low bleeding risk might benefit from prolonged treatment with ticagrelor over 12 months. However, additional research is required to define the target population for this treatment strategy.

The promising results of the PLATO and PEGASUS TIMI 54 trials were not confirmed in the PHILO study (Phase the International Study of Ticagrelor and Clinical Outcomes in Asian ACS Patients) and a substudy in the Asian cohort of the PLATO-US, undermining the benefits of ticagrelor in Asian patients. ${ }^{15,16}$ Both in PHILO and in the Asian cohort of PLATO-US there was a tendency toward more death, AMI, and AIS in patients treated with ticagrelor compared with clopidogrel (hazard ratio, $1.47 ; 95 \%$ confidence interval [CI]: 0.88-2.44 in PHILO and 0.68-2.01 in the PLATO-US cohort). Additionally, there were more major bleedings on ticagrelor in the PHILO study, whereas the bleeding rate in the PLATO-US cohort study was not increased, and comparable with the rest of the PLATO study. ${ }^{15,17}$ Nevertheless, the higher rate of ischemic events in Asian patients calls for further investigation regarding the benefits of ticagrelor administration in Asian populations.

Ticagrelor was not superior to clopidogrel when combined with anticoagulant therapy. A study that compared a double therapy comprising ticagrelor and warfarin with a triple therapy comprising ASA, clopidogrel, and warfarin demonstrated a comparable rate of thrombotic and bleeding events in both groups. ${ }^{18}$ Additionally, in the GEMINI ACS-1 (A Study to Compare the Safety of Rivaroxaban Versus Acetylsalicylic Acid in Addition to Either Clopidogrel or Ticagrelor Therapy in Participants with Acute Coronary Syndrome) trial, the rate of thrombotic and bleeding events for rivaroxaban versus aspirin was similar in the ticagrelor group compared with the clopidogrel group. However, the choice of clopidogrel or ticagrelor during the trial was not randomized, but was rather based on the investigator's preference. These analyses are exploratory and leave space for various hypotheses. In the absence of sufficient efficacy and safety data, the use of ticagrelor or prasugrel as a part of triple therapy is not recommended. ${ }^{19}$

Indirect comparison of the two cornerstone studies comparing the efficacy of ticagrelor and prasugrel (PLATO and TRITON TIMI 38) revealed that prasugrel results in greater reduction of PLATO-defined primary endpoints (overall CV death, AMI, ischemic stroke) and mortality in STEMI groups, with no difference in primary endpoint in patients with non-ST segment elevation myocardial infarction (NSTEMI; Figure 1). Moreover, prasugrel increased the
A

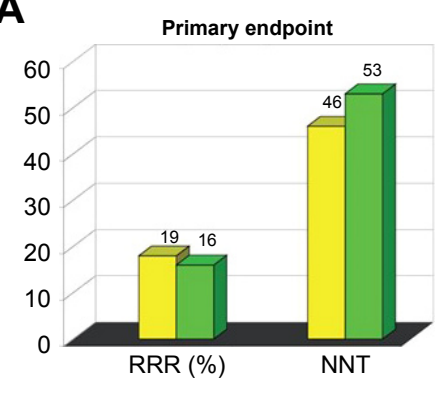

B

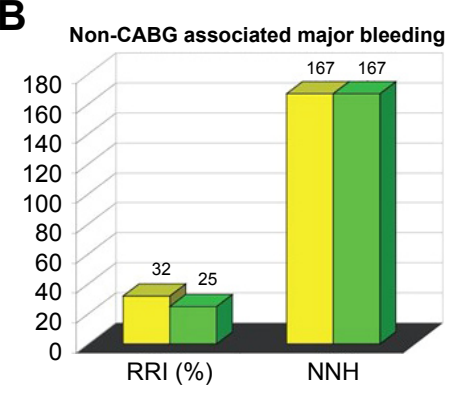

C

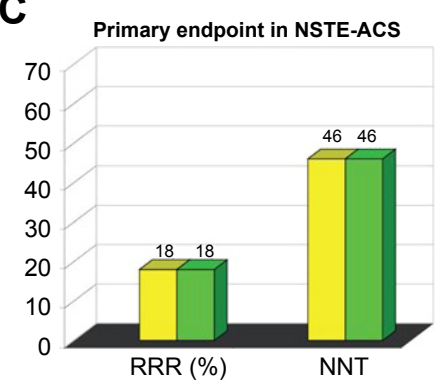

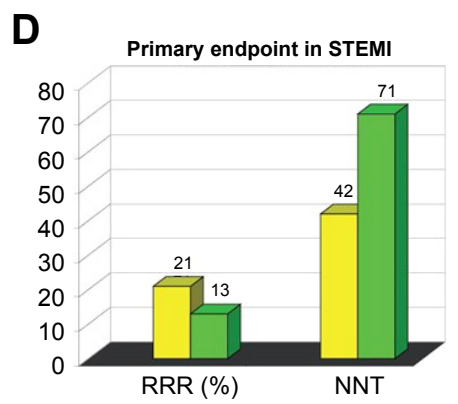

E

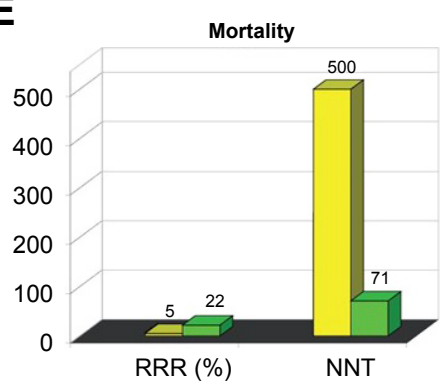

$\square$ TRITON TIMI 38: prasugrel + aspirin vs clopidogrel + aspirin $\square$ PLATO: ticagrelor + aspirin vs clopidogrel + aspirin

Figure I Ticagrelor versus prasugrel - efficiency and safety comparison.

Notes: Differences between (A) PLATOs-defined overall primary endpoint risk (myocardial infarction, stroke, death from vascular causes); (B) non-CABG-associated major bleeding risk; (C) PLATO-defined primary endpoint risk in NSTE-ACS patients; (D) PLATO-defined primary endpoint risk in STEMI patients; and (E) PLATO-defined overall mortality risk among PLATO and TRITON TIMI (Prasugrel versus Clopidogrel in Patients with Acute Coronary Syndromes) 38 studies.

Abbreviations: RRR, relative risk reduction; NNT, number needed to treat; RRI, relative risk increase; NNH, number needed to harm; CABG, coronary artery bypass graft; NSTE-ACS, non-ST-elevation acute coronary state; STEMI, ST segment elevation myocardial infarction. 
risk of non-coronary artery bypass graft (CABG)-associated major bleeding. However, two studies and one meta-analysis which compared ticagrelor and prasugrel directly in terms of the reduction of PLATO-defined efficacy and safety endpoints showed no differences in CV mortality, the rate of AMI and AIS at 1 and 3 months. ${ }^{16-18}$ Importantly, the latter study and the meta-analysis showed reduced rate of stent thrombosis in patients receiving prasugrel, which, however, did not translate into reduced mortality. ${ }^{20,21}$ The reduced rate of stent thrombosis on prasugrel may be due to stronger and more rapid platelet inhibition by prasugrel, compared to ticagrelor. ${ }^{22}$ Interestingly, in patients with AMI and type 2 $\mathrm{DM}$, ticagrelor seems to demonstrate greater inhibition of ADP-induced platelet reactivity in comparison to prasugrel, in both the acute and chronic phases of treatment. ${ }^{23}$

The difference in bleeding risk between ticagrelor and prasugrel remains unclear (Table 2 ). The previously mentioned meta-analysis demonstrated that ticagrelor is associated with a numerically, albeit nonsignificant, lower risk of major bleeding than prasugrel during 1 year follow-up. ${ }^{13}$ However, a real-world comparison of ticagrelor and prasugrel in 16,098 patients with ACS demonstrated a significantly lower rate of major bleeding events on prasugrel during 1-month follow-up. ${ }^{24}$ More studies are required to identify the P2Y12 antagonist associated with the lowest bleeding rate. Interestingly, a trial in which recombinant activated factor VII, fibrinogen concentrate, and factor XIII concentrate were used to overcome antiplatelet effect by acting on fibrin formation or fibrinolysis may point to the cessation of ticagrelor-related unrestrained bleeding. ${ }^{25}$

\section{Ticagrelor drug-drug interactions in ACS}

Among interactions with other drugs, concomitant use of ticagrelor with morphine, statins, and digoxin seems relevant. ${ }^{4}$ Morphine has been reported to reduce the absorption of ticagrelor by its inhibitory effect on gastric motility. ${ }^{26}$ Studies performed on patients with AMI receiving ticagrelor and either morphine or placebo demonstrated diminished and delayed antiplatelet effect in the morphine group. Additionally, a clinically relevant decrease of maximal serum concentrations of both ticagrelor and its active metabolite and prolonged clearance of ticagrelor were observed. ${ }^{27,28}$ Interestingly, in healthy volunteers a similar decrease of concentration of ticagrelor achieved by a comparable dose of morphine was observed, although platelet inhibition remained adequate. ${ }^{29}$ It is likely that the publication of the results of IMPRESSION (Influence of Morphine on Pharmacokinetics and Pharmacodynamics of Ticagrelor in Patients with Acute Myocardial Infarction) trial will elucidate this interaction. ${ }^{30}$

In addition, morphine causes, via a similar mechanism, significant decrease in the action of clopidogrel. ${ }^{31}$ Current European Society of Cardiology guidelines for the management of AMI recommend intravenous morphine titration in severe pain, however indicating the possibility of failure of antiplatlet effect due to interaction with morphine. ${ }^{32}$

Revision of results of the PLATO trial which focused on the interaction between ticagrelor and statins concluded that co-administration of ticagrelor and statins decreased both vascular and all-cause mortality, compared to clopidogrel and statins. ${ }^{29}$ Increased concentration of simvastatin in the presence of ticagrelor was confirmed also in healthy volunteers. ${ }^{33}$ These results have been attributed to the fact that ticagrelor, in contrast to clopidogrel, weakly inhibits CYP450 3A4 and delays metabolism of certain statins, especially simvastatin. Both ticagrelor and rosuvastatin were shown to increase the concentration of adenosine in animal models, which may further contribute to the beneficial effect of their co-administration. ${ }^{34,35}$ Nevertheless, a series of case studies have reported an increased risk of rhabdomyolysis when ticagrelor was co-administrated with high-dose statins in patients with $\mathrm{CKD}$, suggesting that the ticagrelor-statins interaction may be clinically relevant in particular patient populations..$^{36,37}$

The co-administation of ticagrelor with digoxin warrants caution as well. Because ticagrelor is a weak inhibitor of P-glycoprotein, which is involved in the metabolism of digoxin, the concentration of digoxin may increase once ticagrelor is initiated. Hence, in patients treated with ticagrelor the concentration of digoxin should be monitored. ${ }^{38}$

\section{Genetic polymorphism}

The genetic background of ticagrelor response has been investigated previously in several pharmacogenetics studies, but the genetic determination of ticagrelor response in humans still remains unknown. The PLATO trial demonstrated that ticagrelor reduces the rate of a combined endpoint of $\mathrm{CV}$ death, AMI, or stroke with no increase in the incidence of major bleeding as compared to clopidogrel, irrespective of cytochrome P450 2C19 (CYP2C19) and adenosine triphosphate (ATP) binding cassette subfamily $\mathrm{B}(A B C B 1)$ genetic polymorphisms. ${ }^{39}$ In the genetic substudy of the PLATO trial, a two-phase design was used for a genomewide association study (GWAS): a discovery phase, which consisted of 3,998 individuals genotyped, and a replication phase of an additional 6,015 individuals. The GWAS results on ticagrelor pharmacokinetics in a large cohort of 
ticagrelor-treated ACS patients showed an association of three different genetic loci (SLCO1B1-rs4149056, CYP3A4rs62471956, rs56324128, and UGT2B7-rs61361928) with ticagrelor levels. Importantly, the modest genetic impact on plasma levels of ticagrelor and the active metabolite of ticagrelor (AR-C124910XX [ARC]) did not translate into effect on any efficacy (ie, CV death, MI, and stroke) or safety endpoints (ie, non-CABG-related bleeds or investigatorreported dyspnea).$^{40}$ In a recent study, the impact of genetic variations within both ITGA $2 B$ and ITGB3 encoding genes on ex vivo antiplatelet effects of ticagrelor in Chinese healthy subjects was studied. In 28 carriers of ITGA2B rs5911GG genotype was associated with lower level of platelet ADPinduced platelet activation after incubation with ticagrelor. The study showed that the SNP can decrease the ex vivo antiplatelet activity of ticagrelor, especially at low concentration, though the baseline platelet activity was not affected by the polymorphism. However, the ITGB3 rs4642 or rs 4634 polymorphisms had no effect on either the baseline platelet activity or the ex vivo antiplatelet effect of ticagrelor. ${ }^{41}$ In another study, the same group of researchers further evaluated a population of 196 healthy Chinese volunteers in order to analyze the association between platelet reactivity with or without ticagrelor and nine P2Y12 SNPs (rs1907637 C.T, rs79320243 A.G/htSNP, rs 10935842 A.T/htSNP, rs6787801 T.C/htSNP, rs6801273 A.G, rs16863323 G.A, rs2046934 T.C, rs6785930 C.T, and rs6809699 G.T/htSNP) and the GNB3 rs5443 C.T polymorphism. ${ }^{42}$ However, genetic variations in P2Y12 and GNB3 were not associated with interindividual variability in platelet inhibition after partial ex vivo blockade with ticagrelor. The abovementioned observations stand in line with the first study, which observed that SNPs in P2Y12, P2Y1, and ITGB3 do not affect ticagrelor-induced inhibition of ADP-induced platelet aggregation. ${ }^{43}$ In another study conducted in healthy Chinese male subjects, eight different SNPs within PEAR1 gene were evaluated in order to analyze their association with in vitro platelet reactivity and ticagrelor pharmacokinetics. It was found that PEARI rs 12041331 polymorphism is associated with in vitro antiplatelet activity of ticagrelor but no significant difference in ticagrelor pharmacokinetics with the rs 12041331 genotype was observed. Minor homozygotes of two SNPs (rs12041331, rs 12566888) exhibited statistically significant lower maximal platelet activation and minor allele carriers of rs4661012 polymorphism exhibited statistically significant higher maximal platelet activation. PEAR1 intronic variant rs12041331 AA genotype and 3'-UTR variant rs4661012 $G G$ genotype were associated with an increased IPA after in vitro ticagrelor incubation at low and high concentrations, respectively. However, the mechanisms by which rs12041331 polymorphism influences ticagrelor response remain unknown. No significant difference in the pharmacokinetic parameters of ticagrelor and ARC were observed among PEARl genotypes of candidate SNPs. ${ }^{44}$ At present, there are no data supporting any impact of genetic polymorphisms in the pharmacokinetics of ticagrelor on clinical outcomes of patients.

\section{Mechanism underlying the pleiotropic effects of ticagrelor}

The results of the PLATO trial were embraced with growing interest in the extra-platelet effects of ticagrelor. Ticagrelor administration was shown to be associated with the increased concentration of adenosine caused by 1 ) inhibition of adenosine reuptake by blocking human equilibrative nucleoside transporter $1,{ }^{45}$ and 2 ) increased release of ATP, subsequently transformed into adenosine. ${ }^{46}$

Although ticagrelor was proved to elevate serum adenosine levels only in higher doses than standard, a similarity between part of pleiotropic effects exerted by ticagrelor and those mediated by adenosine was proved and described. ${ }^{47,48}$ This may suggest that some pleiotropic effects of ticagrelor are achieved via adenosine-dependent mechanism. Effects induced by an increased concentration of adenosine and stimulation of adenosine receptors (A1-A3) are summarized in Table $3 .{ }^{49,50}$ Comparably, probable adenosine-dependent pleiotropic effects of ticagrelor together with pleiotropic mechanisms of unknown origin and mechanisms underlying the adenosine inhibition reuptake are presented in Figure 2.

The first described pleiotropic effect was decreased death rate in patients with ACS receiving ticagrelor (PLATO subgroup) who presented with sepsis or pulmonary infection. ${ }^{51}$ This phenomenon was proposed to be based on adenosinerelated depletion of pro-inflammatory factors by acting on A2A and A2B adenosine receptors, as well as on decreased platelet reactivity, and thus prevention of disseminated intravascular coagulation. ${ }^{52,53}$ In another study, vasodilation of coronary arteries and increased coronary blood flow velocity (CBFV) were described in patients with NSTEMI undergoing percutaneous coronary intervention. Ticagrelor exhibited higher maximal $\mathrm{CBFV} /$ baseline $\mathrm{CBFV}$ ratio than prasugrel at increasing concentrations of adenosine infusion rate, confirming that the increased $\mathrm{CBFV}$ on ticagrelor is associated with the inhibition of adenosine reuptake. ${ }^{54}$ In a study performed on diabetic rats, ticagrelor in combination 
Table 3 Effects induced by stimulation of membrane-bound adenosine receptors (AI-A3)

\begin{tabular}{|c|c|c|c|}
\hline $\begin{array}{l}\text { Adenosine } \\
\text { receptors }\end{array}$ & Ticagrelor-relevant role & $\begin{array}{l}\text { Impact on } \\
\text { cell cAMP }\end{array}$ & $\begin{array}{l}\text { Concentration of adenosine } \\
\text { required for activation }\end{array}$ \\
\hline $\mathrm{Al}$ & $\begin{array}{l}\text { - Coronary vessel spasm } \\
\text { - Promotion of neutrophil chemotaxis and phagocytosis } \\
\text { - Negative chronotropic effect } \\
\text { - Dyspnea } \\
\text { - GFR decrease }\end{array}$ & Decrease & Low \\
\hline $\mathrm{A} 2 \mathrm{a}$ & $\begin{array}{l}\text { - Coronary vessel dilation } \\
\text { - EPC migration } \\
\text { - Inhibition of platelet activation } \\
\text { - Dyspnea } \\
\text { - Inhibition of neutrophil trafficking, granule release, and } \\
\text { production of inflammatory mediators }\end{array}$ & Increase & Low \\
\hline$A 2 b$ & $\begin{array}{l}\text { - Coronary vessel dilation } \\
\text { - Inhibition of platelet activation } \\
\text { - Inhibition of neutrophil trafficking, granule release } \\
\text { - Inhibition of production of inflammatory mediators }\end{array}$ & Increase & High \\
\hline A3 & $\begin{array}{l}\text { - Coronary vessel spasm } \\
\text { - EPC migration } \\
\text { - Promotion of neutrophil chemotaxis and phagocytosis }\end{array}$ & Decrease & Low \\
\hline
\end{tabular}

Abbreviations: cAMP, cyclic adenosine monophosphate; GFR, glomerular filtration rate; EPC, endothelial progenitor cell.

with rosuvastatin decreased the infarct size due to more potent adenosine-dependent myocardial reperfusion. ${ }^{34}$ Ticagrelor was shown to increase the concentration of (cluster of differentiation) $\mathrm{CD} 34^{+} / \mathrm{CD} 133^{+}$endothelial progenitor cells (EPC) in peripheral blood, which are responsible for endothelial regeneration in patients after ACS..$^{55}$ The mechanism underlying the increased concentration of EPC is adenosine-modulated migration of EPC instigated by activation

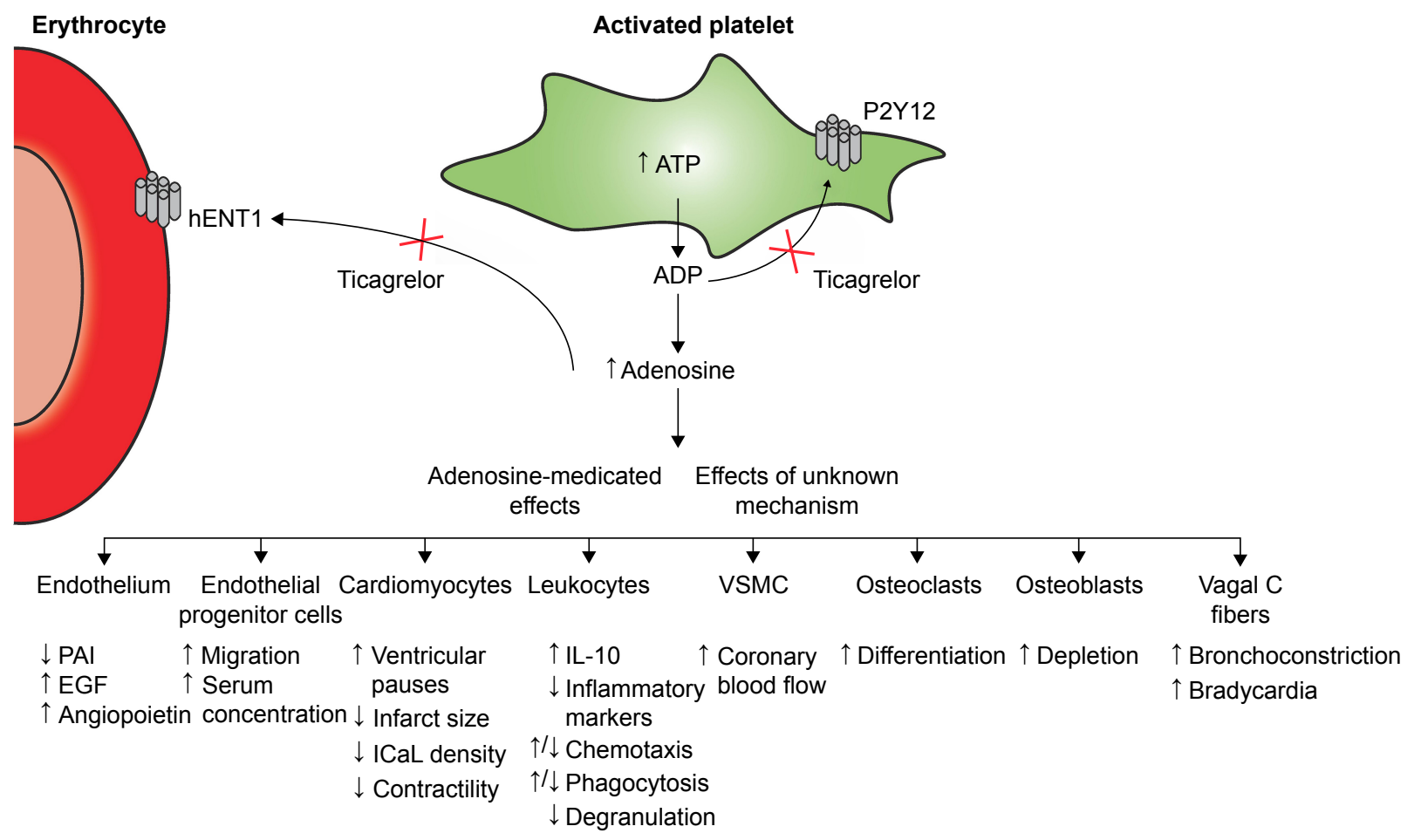

Figure 2 Mechanisms underlying the probable adenosine-dependent and non-adenosine-dependent pleiotropic effects of ticagrelor.

Abbreviations: ICaL, L-type $\mathrm{Ca}(2+)$ currents in cardiomyocytes; PAI, plasminogen activation inhibitor; EGF, endothelial growth factor; IL-I0, interleukin I0; hENTI, human equilibrative nucleoside transporter I; ATP, adenosine triphosphate; ADP, adenosine diphosphate; VSMC, vascular smooth muscle cells. 
of $\mathrm{A} 2 \mathrm{~A}$ and $\mathrm{A} 3$ receptors as well as increased production of endothelial growth factor, interleukin-8 and angiopoietin-1 in endothelial cells, monocytes, and macrophages. ${ }^{56-59}$ Ticagrelor was also shown to inhibit differentiation of osteoclasts and promote differentiation of osteoblasts via adenosine A2A receptors in vitro. ${ }^{60}$ Another pleiotropic effect of ticagrelor includes reduced expression and activity of tissue factor and plasminogen activator inhibitor-1 in left atrium appendage endocardial cells isolated from patients with atrial fibrillation, which might translate into reduced risk of stroke and other ischemic events due to thrombus formation in the left atrium. ${ }^{61}$ On the contrary, ticagrelor has been proved to reduce L-type $\mathrm{Ca}(2+)$ current density in rat ventricular myocytes as well as to decrease sarcomere shortening of electrically stimulated cardiomyocytes. ${ }^{62}$

The increased serum concentration of adenosine seems to be responsible also for ticagrelor-related adverse effects, including dyspnea, ventricular pauses, bradycardia, and bradyarrhythmias. Table 4 summarizes the most frequent adverse effects of ticagrelor in patients with ACS, coronary artery disease, and pulmonary disease (asthma, chronic obstructive pulmonary disease [COPD]). Dyspnea during ticagrelor administration and during simultaneous adenosine infusion was confirmed in numerous studies. ${ }^{63-65}$ Dyspnea is caused by adenosine acting on $\mathrm{A} 1$ and $\mathrm{A} 2 \mathrm{~A}$ receptors present on $\mathrm{C}$ fibers of vagal nerve causing bronchoconstriction. ${ }^{66}$ Ticagrelor-related dyspnea is described as sudden and unexpected air hunger or unsatisfied inspiration, and in most cases is recognized as mildly intense. ${ }^{67}$ The diagnosis of ticagrelor-related dyspnea is based on exclusion of other causes of dyspnea. Occurrence of dyspnea varies among trials and depends mainly on the length of administration and dosage of ticagrelor. For example, dyspnea was the reason for ticagrelor discontinuation in 2\%-9\% ACS patients, ${ }^{68}$ whereas dyspnea was not observed in healthy elderly volunteers and mild asthma or mild-to-moderate COPD patients. ${ }^{65}$ The lack of dyspnea in the latter study was probably due to short duration of the trial.

Bradycardia as well as ventricular pauses are side effects of adenosine-related stimulation of adenosine A1 receptor present in heart tissue. ${ }^{69}$ Bradycardia is recognized as a side effect of all oral P2Y12 antagonists; however, it seems to occur more often on ticagrelor. Differences in the incidence of bradycardia in various studies depend on the definition of "bradycardia" (any decrease in the heart rate versus heart rate below 60 beats per minute). Due to chronotropic effect, ticagrelor decreases the heart rate in all patients, but only in a few cases does ticagrelor cause clinically relevant bradycardia. For example, in 300 patients with AMI, ticagrelor was associated with double the risk of bradycardia ( 80 patients) than with clopidogrel (32 patients).$^{70}$ It is not known, however, which clinical event described as bradycardia met the clinical definition of bradycardia, as its incidence varies significantly amidst the trials (PHILO, PLATO, PEGASUS), where bradycardia incidence varied from $1.5 \%$ to $7 \%$. Nevertheless, several cases were reported where ticagrelor induced development of secondary degree type 2 block and complete atrioventricular block. ${ }^{71,72}$

In a substudy of PLATO 5.8\% of patients developed asymptomatic, sinusoid ventricular pauses $(>3 \mathrm{~s})$ during the first week of treatment, which ceased with time. ${ }^{73}$ In the

Table 4 Incidence of the most frequent adverse effects of ticagrelor in patients with acute coronary syndrome, coronary artery disease, and pulmonary disease (asthma, COPD)

\begin{tabular}{|c|c|c|c|c|c|}
\hline Study (year) & $\begin{array}{l}\text { Patients } \\
\text { (n) }\end{array}$ & Follow-up & $\begin{array}{l}\text { Dyspnea } \\
\text { (\%) }\end{array}$ & $\begin{array}{l}\text { Bradycardia } \\
\text { (\%) }\end{array}$ & $\begin{array}{l}\text { Ventricular } \\
\text { pauses (\%) }\end{array}$ \\
\hline \multicolumn{6}{|l|}{ Acute coronary syndromes } \\
\hline PLATO $(2009)^{5}$ & 18,624 & I year & 13.80 & 7.10 & 5.80 \\
\hline PHILO $(2015)^{15}$ & 801 & I year & 5.70 & 2.80 & 0 \\
\hline PEGASUS TIMI $54(90 \mathrm{mg})(2015)^{14}$ & 13,946 & 33 months & 18.9 & 2.04 & 18.9 \\
\hline PEGASUS TIMI $54(60 \mathrm{mg})(2015)^{14}$ & 13,946 & 33 months & 15.4 & 2.32 & 15.4 \\
\hline DISPERSE $2(2010)^{95}$ & 984 & 3 months & 13.0 & $\mathrm{~N} / \mathrm{A}$ & $N / A$ \\
\hline $\begin{array}{l}\text { Ticagrelor versus clopidogrel in non-ST-elevation acute } \\
\text { coronary syndromes }(2016)^{70}\end{array}$ & 149 & I year & $\mathrm{N} / \mathrm{A}$ & 54 & $N / A$ \\
\hline Ticagrelor and bradycardia: a nested case-control study $(2015)^{96}$ & 700 & 2 years & $\mathrm{N} / \mathrm{A}$ & 20 & $N / A$ \\
\hline \multicolumn{6}{|l|}{ Coronary artery disease } \\
\hline DISPERSE I $(2010)^{95}$ & 200 & I month & 14.1 & $\mathrm{~N} / \mathrm{A}$ & $\mathrm{N} / \mathrm{A}$ \\
\hline ONSET/OFFSET (2009) $)^{97}$ & 123 & 6 weeks & 38.60 & $\mathrm{~N} / \mathrm{A}$ & $N / A$ \\
\hline \multicolumn{6}{|l|}{ Pulmonary disease } \\
\hline Healthy volunteers, asthma, or COPD patients $(2013)^{65}$ & 40 & I week & 0 & N/A & $\mathrm{N} / \mathrm{A}$ \\
\hline
\end{tabular}

Abbreviations: N/A, not applicable; COPD, chronic obstructive pulmonary disease; PLATO, Ticagrelor versus Clopidogrel in Patients with Acute Coronary Syndromes; PHILO, Ticagrelor versus Clopidogrel in Japanese, Korean, and Taiwanese Patients with Acute Coronary Syndrome; PEGASUS TIMI 54, Long-Term Use of Ticagrelor in Patients with Prior Myocardial Infarction; DISPERSE, Antiplatelet Therapy in Acute Coronary Syndromes: Focus on Ticagrelor; ONSET/OFFSET, Randomized Double-Blind Assessment of the ONSET and OFFSET of the Antiplatelet Effects of Ticagrelor versus Clopidogrel in Patients with Stable Coronary Artery Disease. 
PHILO and PEGASUS trials the occurrence of ventricular pauses was $0 \%$ and $1.6 \%$, respectively, making ventricular pauses a clinically irrelevant complication. Noteworthy, in one case report both bradycardia and dyspnea were reversed using aminophylline, suggesting that administration of aminophylline might counteract the adenosine-related adverse effects of ticagrelor. ${ }^{74}$

\section{Ticagrelor in non-coronary indications}

Major clinical trials involving ticagrelor in non-coronary indications are included in Table 5.

\section{Ischemic stroke and transient ischemic attacks}

Major evidence of benefits of ticagrelor in AIS or transient ischemic attacks (TIA) arises from the SOCRATES trial (Acute Stroke or Transient Ischemic Attack Treated with Aspirin or Ticagrelor and Patient Outcomes). In SOCRATES, ticagrelor was not superior over ASA in terms of efficacy outcomes in any group of patients. Moreover, both drugs were associated with comparable risk of bleeding and other adverse effects, except for more common dyspnea among patients treated with ticagrelor. ${ }^{75}$ Noteworthy, a subanalysis of the SOCRATES results in Asian patients compared with non-Asian patients demonstrated equal efficacy of ticagrelor in both groups, but a lower risk of major hemorrhage in Asian patients receiving ticagrelor. ${ }^{76}$ The beneficial effects of ticagrelor were hypothesized to be associated with the prior long-term use of ASA, which would result in transient DAPT. ${ }^{77,78}$ In the absence of no clear explanation, as of today, ticagrelor has not been included in the recent guidelines of secondary prevention of stroke. ${ }^{79,80}$

\section{Peripheral arterial disease (PAD)}

The use of ticagrelor seems to be associated with a reduced risk of PAD progression among patients with prior AMI.
A summary of the previous reports could not firmly demonstrate the superiority of either ticagrelor or clopidogrel in the treatment and prevention of the complications of PAD. ${ }^{81-83}$ Ultimately, results of the EUCLID (Examining Use of Ticagrelor in Peripheral Artery) trial conclude that both drugs have a comparable efficacy and safety profile, and that there are no differences in adverse effects. ${ }^{84}$ Nevertheless, novel antiplatelet agents have not yet been introduced in routine pharmacotherapy of PAD. ${ }^{85}$

\section{Coronary artery bypass grafting}

Antithrombotic therapy following the procedure of coronary artery bypass grafting is generally based on ASA. Nevertheless, graft failure due to thrombosis occurs in up to $10 \%$ of cases and therefore P2Y12 inhibitors are incrementally introduced in patients after CABG. A retrospective observation of 705 patients suggests that exposure to ticagrelor shortly before $\mathrm{CABG}$ is associated with a higher risk of hemorrhagic complications. This effect was not observed when ticagrelor was discontinued 3 days prior to surgery. ${ }^{86}$ A study focusing on the turnover of platelets after CABG suggests that ticagrelor is more efficient than clopidogrel in patients, in whom rapid supply of young platelets occurs. ${ }^{87} \mathrm{~A}$ comprehensive insight into the use of ticagrelor after $\mathrm{CABG}$ is anticipated from results of the current TiCAB (Ticagrelor in $\mathrm{CABG}$ ) trial, which aims to compare the efficacy and safety of ticagrelor and ASA after CABG. ${ }^{88}$

\section{Conclusion}

Ticagrelor has the potential to revolutionize the treatment of coronary artery disease and ACS due to reduction of CV death as proved in the PEGASUS TIMI 54 trial, when implemented as a component of DAPT. Ticagrelor seems to demonstrate more potent platelet inhibition in ACS patients with DM and/or COPD, as compared with prasugrel, at equal bleeding risk. $^{22,89}$ Nevertheless, the underperformance of ticagrelor in Asian population shown in the PHILO study needs further

Table 5 Ticagrelor in non-coronary indications

\begin{tabular}{|c|c|c|c|c|c|}
\hline $\begin{array}{l}\text { Study } \\
\text { (year) }\end{array}$ & Study design & $\begin{array}{l}\text { Patients } \\
\text { (n) }\end{array}$ & Follow-up & $\begin{array}{l}\text { Efficacy, OR } \\
(95 \% \mathrm{CI})\end{array}$ & $\begin{array}{l}\text { Safety } \\
\text { (major bleeding), OR (95\% Cl) }\end{array}$ \\
\hline $\begin{array}{l}\text { EUCLID } \\
(2017)^{84}\end{array}$ & $\begin{array}{l}\text { Ticagrelor versus clopidogrel } \\
\text { in PAD }\end{array}$ & 13,855 & $\begin{array}{l}30 \text { months } \\
\text { (median) }\end{array}$ & $\begin{array}{l}I .02(0.92-I .13) \\
p=0.65\end{array}$ & $1.10(0.84-1.43), p=0.49$ \\
\hline $\begin{array}{l}\text { SOCRATES } \\
(2016)^{75}\end{array}$ & $\begin{array}{l}\text { Ticagrelor versus ASA in } \\
\text { acute ischemic stroke and TIA }\end{array}$ & 13,199 & 90 days & $0.87(0.76-1.00)$ & $0.83(0.52-1.34), p=0.45$ \\
\hline $\begin{array}{l}\text { TiCAB } \\
(2016)^{88}\end{array}$ & $\begin{array}{l}\text { Ticagrelor versus ASA after } \\
\text { CABG }\end{array}$ & $500+$ & $\begin{array}{l}12 \text { months } \\
\text { (designed) }\end{array}$ & Currently ongoing & \\
\hline
\end{tabular}

Abbreviations: PAD, peripheral artery disease; ASA, acetylsalicylic acid; TIA, transient ischemic attack; CABG, coronary artery bypass grafting; OR, odds ratio; CI, confidence interval; EUCLID, Ticagrelor versus Clopidogrel in Symptomatic Peripheral Artery Disease; SOCRATES, Ticagrelor versus Aspirin in Acute Stroke or Transient Ischemic Attack; TiCAB, A Randomized, Parallel Group, Double-Blind Study of Ticagrelor Compared with Aspirin for Prevention of Vascular Events in Patients Undergoing Coronary Artery Bypass Graft Operation: Rationale and Design of the Ticagrelor in CABG (TiCAB) trial: An Investigator-Initiated trial. 
investigation. At present, no genetic polymorphisms influencing the metabolism of ticagrelor have been identified to clarify the differences in the efficacy/safety profile of ticagrelor depending on race and comorbidities. The role of ticagrelor in patients with stroke/TIA, PAD, and post-CABG remains limited, as no superiority of ticagrelor over clopidogrel has been shown. Nevertheless, the decreased reuptake of adenosine, which is likely responsible for ticagrelor pleiotropic effects, strengthens the role of ticagrelor in long-term antiplatelet therapy in patients with ACS, as well as in non-ACS indications. For example, ticagrelor might be beneficial in sepsis, as it decreases the concentration of inflammatory biomarkers and modulates the formation of fibrin clots. Regarding the unique pharmacokinetic and pharmacodynamics properties of ticagrelor, as well as the not yet entirely clear pleiotropic effects, ticagrelor remains an active research topic. Once the mechanisms underlying ticagrelor's mode of action are clarified in vivo, the indications of ticagrelor administration are likely to expand.

\section{Disclosure}

Research subject was implemented with CEPT infrastructure financed by the European Union - the European Regional Development Fund within the Operational Program "Innovative economy" for 2007-2013. The study was supported financially as part of the research grant from the National Science Center OPUS research grant (grant number 2013/11/B/NZ7/01541). The authors report no other conflicts of interest in this work.

\section{References}

1. Linden MD, Jackson DE. Platelets: pleiotropic roles in atherogenesis and atherothrombosis. Int J Biochem Cell Biol. 2010;42:1762-1766.

2. Hechler B, Gachet C. Purinergic receptors in thrombosis and inflammation. Arterioscler Thromb Vasc Biol. 2015;35:2307-2315.

3. Windecker S, Kolh P, Alfonso F, et al. 2014 ESC/EACTS guidelines on myocardial revascularization: the task force on myocardial revascularization of the European Society of Cardiology (ESC) and the European Association for Cardio-Thoracic Surgery (EACTS). Developed with the special contribution of the European Association of Percutaneous Cardiovascular Interventions (EAPCI). Eur Heart J. 2014;35: 2541-2619.

4. Roffi M, Patrono C, Collet JP, et al. 2015 ESC guidelines for the management of acute coronary syndromes in patients presenting without persistent ST-segment elevation: task force for the management of acute coronary syndromes in patients presenting without persistent ST-segment elevation of the European Society of Cardiology (ESC). Eur Heart J. 2016;37:267-315.

5. Wallentin L, Becker RC, Budaj A, et al. Ticagrelor versus clopidogrel in patients with acute coronary syndromes. N Engl J Med. 2009;361: $1045-1057$

6. Wiviott $\mathrm{SD}$, Braunwald E, McCabe $\mathrm{CH}$, et al. Prasugrel versus clopidogrel in patients with acute coronary syndromes. N Engl J Med. 2007; 357:2001-2015.

7. Zhang Y, Zhang S, Ding Z. Role of P2Y12 receptor in thrombosis. Adv Exp Med Biol. 2017;906:307-324.
8. Burnstock G. Purinergic signalling: therapeutic developments. Front Pharmacol. 2017;8:661.

9. Lecchi A, Femia EA, Paoletta S, et al. Inherited dysfunctional platelet P2Y12 receptor mutations associated with bleeding disorders. Hamostaseologie. 2016;36:279-283.

10. Teng R. Ticagrelor: pharmacokinetic, pharmacodynamic and pharmacogenetic profile: an update. Clin Pharmacokinet. 2015;54:1125-1138.

11. Meves SH, Schroder KD, Endres HG, Krogias C, Kruger JC, Neubauer H. Clopidogrel high-on-treatment platelet reactivity in acute ischemic stroke patients. Thromb Res. 2014;133:396-401.

12. Sahlen A, Varenhorst C, Lagerqvist B, et al. Outcomes in patients treated with ticagrelor or clopidogrel after acute myocardial infarction: experiences from SWEDEHEART registry. Eur Heart J. 2016;37: 3335-3342.

13. Shah R, Rashid A, Hwang I, Fan TM, Khouzam RN, Reed GL. Metaanalysis of the relative efficacy and safety of oral P2Y12 inhibitors in patients with acute coronary syndrome. Am J Cardiol. 2017;119:1723-1728.

14. Bonaca MP, Bhatt DL, Cohen M, et al. Long-term use of ticagrelor in patients with prior myocardial infarction. $N$ Engl J Med. 2015;372: 1791-1800.

15. Goto S, Huang CH, Park SJ, Emanuelsson H, Kimura T. Ticagrelor vs clopidogrel in Japanese, Korean and Taiwanese patients with acute coronary syndrome - randomized, double-blind, phase III PHILO study. Circ J. 2015;79:2452-2460.

16. Serebruany VL, Tomek A, Pya Y, Bekbossynova M, Kim MH. Inferiority of ticagrelor in the PHILO trial: play of chance in East Asians or nightmare confirmation of PLATO-USA? Int J Cardiol. 2016;215: 372-376.

17. Kang HJ, Clare RM, Gao R, et al. Ticagrelor versus clopidogrel in Asian patients with acute coronary syndrome: a retrospective analysis from the Platelet Inhibition and Patient Outcomes (PLATO) trial. Am Heart J. 2015;169:899-905.

18. Braun OO, Bico B, Chaudhry U, et al. Concomitant use of warfarin and ticagrelor as an alternative to triple antithrombotic therapy after an acute coronary syndrome. Thromb Res. 2015;135:26-30.

19. Levine GN, Bates ER, Bittl JA, et al. 2016 ACC/AHA guideline focused update on duration of dual antiplatelet therapy in patients with coronary artery disease: a report of the American College of Cardiology/ American Heart Association task force on clinical practice guidelines. J Thorac Cardiovasc Surg. 2016;152:1243-1275.

20. Rollini F, Franchi F, Cho JR, et al. A head-to-head pharmacodynamic comparison of prasugrel vs. ticagrelor after switching from clopidogrel in patients with coronary artery disease: results of a prospective randomized study. Eur Heart J. 2016;37:2722-2730.

21. Sucato V, Corrado E, Castellana C, et al. Real-world use of ticagrelor and prasugrel in patients with NSTEMI undergoing percutaneous coronary intervention. J Cardiovasc Med (Hagerstown). 2017;18(6):450-451.

22. Franchi F, Rollini F, Cho JR, et al. Impact of escalating loading dose regimens of ticagrelor in patients with ST-segment elevation myocardial infarction undergoing primary percutaneous coronary intervention: results of a prospective randomized pharmacokinetic and pharmacodynamic investigation. JACC Cardiovasc Interv. 2015;8:1457-1467.

23. Franchi F, Rollini F, Aggarwal N, et al. Pharmacodynamic comparison of prasugrel versus ticagrelor in patients with type 2 diabetes mellitus and coronary artery disease: the OPTIMUS (Optimizing Antiplatelet Therapy in Diabetes Mellitus)-4 study. Circulation. 2016;134:780-792.

24. Larmore C, Effron MB, Molife C, et al. "Real-world" comparison of prasugrel with ticagrelor in patients with acute coronary syndrome treated with percutaneous coronary intervention in the United States. Catheter Cardiovasc Interv. 2016;88:535-544.

25. Calmette L, Martin AC, Le Bonniec B, et al. Ticagrelor reversal: in vitro assessment of four haemostatic agents. J Clin Pathol. 2017;70(9): 733-739.

26. Kubica J, Kubica A, Jilma B, et al. Impact of morphine on antiplatelet effects of oral P2Y12 receptor inhibitors. Int J Cardiol. 2016;215: 201-208. 
27. Kubica J, Adamski P, Ostrowska M, et al. Morphine delays and attenuates ticagrelor exposure and action in patients with myocardial infarction: the randomized, double-blind, placebo-controlled IMPRESSION trial. Eur Heart J. 2016;37:245-252.

28. Parodi G, Bellandi B, Xanthopoulou I, et al. Morphine is associated with a delayed activity of oral antiplatelet agents in patients with STelevation acute myocardial infarction undergoing primary percutaneous coronary intervention. Circ Cardiovasc Interv. 2015;8:e001593.

29. Hobl EL, Reiter B, Schoergenhofer C, et al. Morphine decreases ticagrelor concentrations but not its antiplatelet effects: a randomized trial in healthy volunteers. Eur J Clin Invest. 2016;46:7-14.

30. Kubica J, Adamski P, Ostrowska M, et al. Influence of morphine on pharmacokinetics and pharmacodynamics of ticagrelor in patients with acute myocardial infarction (IMPRESSION): study protocol for a randomized controlled trial. Trials. 2015;16:198.

31. Wang ZY, Chen M, Zhu LL, et al. Pharmacokinetic drug interactions with clopidogrel: updated review and risk management in combination therapy. Ther Clin Risk Manag. 2015;11:449-467.

32. Ibanez B, James S, Agewall S, et al. 2017 ESC guidelines for the management of acute myocardial infarction in patients presenting with ST-segment elevation: the task force for the management of acute myocardial infarction in patients presenting with ST-segment elevation of the European Society of Cardiology (ESC). Eur Heart J. Epub 2017 Aug 26.

33. Teng R, Mitchell PD, Butler KA. Pharmacokinetic interaction studies of co-administration of ticagrelor and atorvastatin or simvastatin in healthy volunteers. Eur J Clin Pharmacol. 2013;69:477-487.

34. Birnbaum Y, Birnbaum GD, Birnbaum I, Nylander S, Ye Y. Ticagrelor and rosuvastatin have additive cardioprotective effects via adenosine. Cardiovasc Drugs Ther. 2016;30:539-550.

35. Birnbaum GD, Birnbaum I, Ye Y, Birnbaum Y. Statin-induced cardioprotection against ischemia-reperfusion injury: potential drug-drug interactions. Lesson to be learnt by translating results from animal models to the clinical settings. Cardiovasc Drugs Ther. 2015;29:461-467.

36. van Vuren AJ, de Jong B, Bootsma HP, Van der Veen MJ, Feith GW. Ticagrelor-induced renal failure leading to statin-induced rhabdomyolysis. Neth J Med. 2015;73:136-138.

37. Kido K, Wheeler MB, Seratnahaei A, Bailey A, Bain JA. Rhabdomyolysis precipitated by possible interaction of ticagrelor with high-dose atorvastatin. J Am Pharm Assoc. 2015;55:320-323.

38. Siller-Matula JM, Trenk D, Krahenbuhl S, Michelson AD, Delle-Karth G. Clinical implications of drug-drug interactions with P2Y12 receptor inhibitors. J Thromb Haemost. 2014;12:2-13.

39. Wallentin L, James S, Storey RF, et al. Effect of CYP2C19 and ABCB1 single nucleotide polymorphisms on outcomes of treatment with ticagrelor versus clopidogrel for acute coronary syndromes: a genetic substudy of the PLATO trial. Lancet. 2010;376:1320-1328.

40. Varenhorst C, Eriksson N, Johansson A, et al. Effect of genetic variations on ticagrelor plasma levels and clinical outcomes. Eur Heart J. 2015;36:1901-1912.

41. Li MP, Xiong Y, Xu A, et al. Association of platelet ITGA2B and ITGB3 polymorphisms with ex vivo antiplatelet effect of ticagrelor in healthy Chinese male subjects. Int J Hematol. 2014;99:263-271.

42. Li MP, Tang J, Wen ZP, et al. Influence of P2Y12 polymorphisms on platelet activity but not ex-vivo antiplatelet effect of ticagrelor in healthy Chinese male subjects. Blood Coagul Fibrinolysis. 2015;26: 874-881.

43. Storey RF, Melissa Thornton S, Lawrance R, et al. Ticagrelor yields consistent dose-dependent inhibition of ADP-induced platelet aggregation in patients with atherosclerotic disease regardless of genotypic variations in P2RY12, P2RY1, and ITGB3. Platelets. 2009;20:341-348.

44. Li M, Hu Y, Wen Z, et al. Association of PEAR1 rs12041331 polymorphism and pharmacodynamics of ticagrelor in healthy Chinese volunteers. Xenobiotica. 2017;47(12):1130-1138.

45. van Giezen JJ, Sidaway J, Glaves P, Kirk I, Bjorkman JA. Ticagrelor inhibits adenosine uptake in vitro and enhances adenosine-mediated hyperemia responses in a canine model. J Cardiovasc Pharmacol Ther. 2012;17:164-172.
46. Ohman J, Kudira R, Albinsson S, Olde B, Erlinge D. Ticagrelor induces adenosine triphosphate release from human red blood cells. Biochem Biophys Res Commun. 2012;418:754-758.

47. Cattaneo M, Schulz R, Nylander S. Adenosine-mediated effects of ticagrelor: evidence and potential clinical relevance. J Am Coll Cardiol. 2014;63:2503-2509.

48. van den Berg TN, El Messaoudi S, Rongen GA, et al. Ticagrelor does not inhibit adenosine transport at relevant concentrations: a randomized crossover study in healthy subjects in vivo. PLoS One. 2015;10:e0137560.

49. Laubach VE, French BA, Okusa MD. Targeting of adenosine receptors in ischemia-reperfusion injury. Expert Opin Ther Targets. 2011;15: $103-118$.

50. Cattaneo M, Schulz R, Nylander S. Adenosine-mediated effects of ticagrelor. J Am Coll Cardiol. 2014;63:2503-2509.

51. Storey RF, James SK, Siegbahn A, et al. Lower mortality following pulmonary adverse events and sepsis with ticagrelor compared to clopidogrel in the PLATO study. Platelets. 2014;25:517-525.

52. Muller KA, Chatterjee M, Rath D, Geisler T. Platelets, inflammation and anti-inflammatory effects of antiplatelet drugs in ACS and CAD. Thromb Haemost. 2015;114:498-518.

53. Hasko G, Cronstein BN. Adenosine: an endogenous regulator of innate immunity. Trends Immunol. 2004;25:33-39.

54. Alexopoulos D, Moulias A, Koutsogiannis N, et al. Differential effect of ticagrelor versus prasugrel on coronary blood flow velocity in patients with non-ST-elevation acute coronary syndrome undergoing percutaneous coronary intervention: an exploratory study. Circ Cardiovasc Interv. 2013;6:277-283.

55. Bonello L, Frere C, Cointe S, et al. Ticagrelor increases endothelial progenitor cell level compared to clopidogrel in acute coronary syndromes: a prospective randomized study. Int J Cardiol. 2015;187:502-507.

56. Fernandez P, Jara C, Aguilera V, et al. Adenosine A(2)A and A(3) receptors are involved in the human endothelial progenitor cells migration. J Cardiovasc Pharmacol. 2012;59:397-404.

57. Dubey RK, Gillespie DG, Jackson EK. A(2B) adenosine receptors stimulate growth of porcine and rat arterial endothelial cells. Hypertension. 2002;39:530-535.

58. Shen J, Halenda SP, Sturek M, Wilden PA. Cell-signaling evidence for adenosine stimulation of coronary smooth muscle proliferation via the A1 adenosine receptor. Circ Res. 2005;97:574-582.

59. Clark AN, Youkey R, Liu X, et al. A1 adenosine receptor activation promotes angiogenesis and release of VEGF from monocytes. Circ Res. 2007;101:1130-1138.

60. Mediero A, Wilder T, Reddy VS, et al. Ticagrelor regulates osteoblast and osteoclast function and promotes bone formation in vivo via an adenosine-dependent mechanism. FASEB J. 2016;30:3887-3900.

61. Reiner MF, Breitenstein A, Holy EW, et al. Ticagrelor, but not clopidogrel active metabolite, displays antithrombotic properties in the left atrial endocardium. Eur Heart J. 2017;38(12):916-919.

62. Kucuk M, Celen MC, Yamasan BE, Olgar Y, Ozdemir S. Effects of ticagrelor on ionic currents and contractility in rat ventricular myocytes. Cardiovasc Drugs Ther. 2015;29:419-424.

63. Wittfeldt A, Emanuelsson H, Brandrup-Wognsen G, et al. Ticagrelor enhances adenosine-induced coronary vasodilatory responses in humans. J Am Coll Cardiol. 2013;61:723-727.

64. Storey RF, Bliden KP, Patil SB, et al. Incidence of dyspnea and assessment of cardiac and pulmonary function in patients with stable coronary artery disease receiving ticagrelor, clopidogrel, or placebo in the ONSET/OFFSET study. J Am Coll Cardiol. 2010;56:185-193.

65. Butler K, Maya J, Teng R. Effect of ticagrelor on pulmonary function in healthy elderly volunteers and asthma or chronic obstructive pulmonary disease patients. Curr Med Res Opin. 2013;29:569-577.

66. Unverdorben M, Parodi G, Pistolesi M, Storey RF. Dyspnea related to reversibly-binding P2Y12 inhibitors: a review of the pathophysiology, clinical presentation and diagnostics. Int J Cardiol. 2016;202:167-173.

67. Storey RF, Becker RC, Harrington RA, et al. Characterization of dyspnoea in PLATO study patients treated with ticagrelor or clopidogrel and its association with clinical outcomes. Eur Heart J. 2011;32:2945-2953. 
68. Harding SA, Van Gaal WJ, Schrale R, et al. Practical experience with ticagrelor: an Australian and New Zealand perspective. Curr Med Res Opin. 2015;31:1469-1477.

69. Mustafa SJ, Morrison RR, Teng B, Pelleg A. Adenosine receptors and the heart: role in regulation of coronary blood flow and cardiac electrophysiology. Handb Exp Pharmacol. 2009;193:161-188.

70. Ren Q, Ren C, Liu X, Dong C, Zhang X. Ticagrelor vs. clopidogrel in nonST-elevation acute coronary syndromes. Herz. 2016;41:246-249.

71. Sharma M, Mascarenhas DA. Ticagrelor associated heart block: the need for close and continued monitoring. Case Rep Cardiol. 2017;2017: 5074891.

72. Goldberg A, Rosenfeld I, Nordkin I, Halabi M. Life-threatening complete atrioventricular block associated with ticagrelor therapy. Int $J$ Cardiol. 2015;182:379-380.

73. Scirica BM, Cannon CP, Emanuelsson H, et al. The incidence of bradyarrhythmias and clinical bradyarrhythmic events in patients with acute coronary syndromes treated with ticagrelor or clopidogrel in the PLATO (Platelet Inhibition and Patient Outcomes) trial: results of the continuous electrocardiographic assessment substudy. $J$ Am Coll Cardiol. 2011;57:1908-1916.

74. Minner SA, Simone P, Chung BB, Shah AP. Successful reversal of bradycardia and dyspnea with aminophylline after ticagrelor load. $J$ Pharm Pract. Epub 2016 Dec 5.

75. Johnston SC, Amarenco P, Albers GW, et al. Ticagrelor versus aspirin in acute stroke or transient ischemic attack. N Engl J Med. 2016; 375:35-43.

76. Wang Y, Minematsu K, Wong KS, et al. Ticagrelor in acute stroke or transient ischemic attack in Asian patients: from the SOCRATES trial (Acute Stroke or Transient Ischemic Attack Treated with Aspirin or Ticagrelor and Patient Outcomes). Stroke. 2017;48:167-173.

77. Moris D, Bakoyiannis C, Avgerinos E. Letter by Moris et al regarding article, "Ticagrelor in acute stroke or transient ischemic attack in Asian patients: from the SOCRATES trial (Acute Stroke or Transient Ischemic Attack Treated with Aspirin or Ticagrelor and Patient Outcomes)". Stroke. 2017;48:e110.

78. Amarenco P, Albers GW, Denison H, et al. Efficacy and safety of ticagrelor versus aspirin in acute stroke or transient ischaemic attack of atherosclerotic origin: a subgroup analysis of SOCRATES, a randomised, double-blind, controlled trial. Lancet Neurol. 2017;16:301-310.

79. Bayona H, Owolabi M, Feng W, et al. A systematic comparison of key features of ischemic stroke prevention guidelines in low- and middle-income vs. high-income countries. J Neurol Sci. 2017;375: 360-366.

80. Coutts SB, Wein TH, Lindsay MP, et al. Canadian Stroke Best Practice Recommendations: secondary prevention of stroke guidelines, update 2014. Int J Stroke. 2015;10:282-291.

81. Spiliopoulos S, Katsanos K, Pastromas G, et al. Initial experience with ticagrelor in patients with critical limb ischemia and high on-clopidogrel platelet reactivity undergoing complex peripheral endovascular procedures. Cardiovasc Intervent Radiol. 2014;37:1450-1457.

82. Katsanos K, Spiliopoulos S, Saha P, et al. Comparative efficacy and safety of different antiplatelet agents for prevention of major cardiovascular events and leg amputations in patients with peripheral arterial disease: a systematic review and network meta-analysis. PLoS One. 2015;10:e0135692.
83. Spiliopoulos S, Pastromas G. Current status of high on-treatment platelet reactivity in patients with coronary or peripheral arterial disease: mechanisms, evaluation and clinical implications. World J Cardiol. 2015;7: 912-921.

84. Hiatt WR, Fowkes FG, Heizer G, et al. Ticagrelor versus clopidogrel in symptomatic peripheral artery disease. $N$ Engl J Med. 2017; 376:32-40.

85. Gerhard-Herman MD, Gornik HL, Barrett C, et al. 2016 AHA/ACC guideline on the management of patients with lower extremity peripheral artery disease: a report of the American College of Cardiology/ American Heart Association task force on clinical practice guidelines. J Am Coll Cardiol. 2017;69:e71-e126.

86. Tomsic A, Schotborgh MA, Manshanden JS, Li WW, de Mol BA. Coronary artery bypass grafting-related bleeding complications in patients treated with dual antiplatelet treatment. Eur J Cardiothorac Surg. 2016;50:849-856.

87. Schneider DJ, Chava S. Factors influencing platelet reactivity in patients undergoing coronary artery bypass surgery. Coron Artery Dis. 2016;27:185-190.

88. de Waha A, Sandner S, von Scheidt M, et al. A randomized, parallel group, double-blind study of ticagrelor compared with aspirin for prevention of vascular events in patients undergoing coronary artery bypass graft operation: rationale and design of the Ticagrelor in CABG (TiCAB) trial: an investigator-initiated trial. Am Heart J. 2016; 179:69-76.

89. Campo G, Vieceli Dalla Sega F, Pavasini R, et al. Biological effects of ticagrelor over clopidogrel in patients with stable coronary artery disease and chronic obstructive pulmonary disease. Thromb Haemost. 2017; 117(6):1208-1216.

90. Siller-Matula JM, Trenk D, Schrör K, et al. Response variability to P2Y12 receptor inhibitors. JACC Cardiovasc Interv. 2013;6:1111-1128.

91. Vercellino M, Sanchez FA, Boasi V, et al. Ticagrelor versus clopidogrel in real-world patients with ST elevation myocardial infarction: 1-year results by propensity score analysis. BMC Cardiovasc Disord. 2017;17:97.

92. Jimenez-Britez G, Freixa X, Flores-Umanzor E, et al. Out-of-hospital cardiac arrest and stent thrombosis: ticagrelor versus clopidogrel in patients with primary percutaneous coronary intervention under mild therapeutic hypothermia. Resuscitation. 2017;114:141-145.

93. Beigel R, Iakobishvili Z, Shlomo N, et al. Real-world use of novel P2Y12 inhibitors in patients with acute myocardial infarction: a treatment paradox. Cardiology. 2017;136:21-28.

94. Motovska Z, Hlinomaz O, Miklik R, et al. Prasugrel versus ticagrelor in patients with acute myocardial infarction treated with primary percutaneous coronary intervention: multicenter randomized PRAGUE-18 study. Circulation. 2016;134:1603-1612.

95. Birkeland K, Parra D, Rosenstein R. Antiplatelet therapy in acute coronary syndromes: focus on ticagrelor. J Blood Med. 2010;1:197-219.

96. Turgeon RD, Fernandes KA, Juurlink D, Tu JV, Mamdani M. Ticagrelor and bradycardia: a nested case-control study. Pharmacoepidemiol Drug Saf. 2015;24:1281-1285.

97. Gurbel PA, Bliden KP, Butler K, et al. Randomized double-blind assessment of the ONSET and OFFSET of the antiplatelet effects of ticagrelor versus clopidogrel in patients with stable coronary artery disease: the ONSET/OFFSET study. Circulation. 2009;120:2577-2585.
Therapeutics and Clinical Risk Management

\section{Publish your work in this journal}

Therapeutics and Clinical Risk Management is an international, peerreviewed journal of clinical therapeutics and risk management, focusing on concise rapid reporting of clinical studies in all therapeutic areas, outcomes, safety, and programs for the effective, safe, and sustained use of medicines. This journal is indexed on PubMed Central, CAS,

\section{Dovepress}

EMBase, Scopus and the Elsevier Bibliographic databases. The manuscript management system is completely online and includes a very quick and fair peer-review system, which is all easy to use. Visit http://www.dovepress.com/testimonials.php to read real quotes from published authors. 